\title{
Choledochal Cyst with Aberrant Right Posterior Sectoral Duct
}

\author{
Sumitoj Singh • Narinder Pal Singh • Anirudh Goyal • Satpal Hans • Sudhir Khichy
}

Received: 28 February 2013 / Accepted: 6 May 2013 /Published online: 17 May 2013

(C) Association of Surgeons of India 2013

\begin{abstract}
Choledochal cysts are focal or diffuse dilatations of the biliary tree. Its association with the aberrant hepatic duct is rarely reported. We present the case of a 14-year-old girl having aberrant right posterior sectoral duct with choledochal cyst. It can be missed on cholangiography and during surgery, leading to serious complications. In this case, it was diagnosed on magnetic resonance cholangiopancreatography and was managed along with cyst excision.
\end{abstract}

Keywords Choledochal cysts · Aberrant hepatic duct . Biliary anomalies $\cdot$ Magnetic resonance cholangiopancreatography

\section{Case Summary}

Choledochal cyst association with aberrant hepatic duct (AHD) is rarely reported [1, 2]. A 14-year-old female presented with the complaint of recurrent abdominal pain since 6 months. On magnetic resonance cholangiopancreatography (MRCP), there was diffuse fusiform dilatation $(3 \mathrm{~cm})$ of the proximal and mid common bile duct with involvement of the confluence of the left hepatic duct and right anterior sectoral duct. The right posterior sectoral duct (AHD) was dilated $(1.2 \mathrm{~cm})$ and was opened separately into the choledochal cyst. The cystic duct was of normal calibre and had low insertion (Fig. 1). At surgery, AHD was opening about $3 \mathrm{~cm}$ away from confluence of the right anterior sectoral duct and left hepatic duct and was extending superiorly in the cyst wall. The cyst was transected just at the confluence of the left hepatic and right anterior duct junction. The adjacent walls of the right

\footnotetext{
S. Singh $(\varangle) \cdot$ N. P. Singh $\cdot$ A. Goyal $\cdot$ S. Hans $\cdot$ S. Khichy

Department of General Surgery, Government Medical College,

Amritsar, Punjab 143001, India

e-mail: sumitoj@rediffmail.com
}

posterior sectoral duct and common hepatic duct were sutured and then anastomosed as a single large stoma with Roux-en-Y loop. On follow-up of 1 year, there was no history of pain in the abdomen or cholangitis. Repeat liver function tests and ultrasound were within normal limits.

The biliary and anatomical anomalies reported on the choledochal cyst in the literature are primary ductal stricture which may be hilar, confluent or umbilical; aberrant hepatic duct; low confluence of hepatic ducts; aberrant hepatic artery; and very small hepatic duct $[3,4]$. These have tremendous implications as they are seldom diagnosed preoperatively and can cause significant intra-operative complications and require higher degree of awareness on the part of operating surgeon.

On literature review, only nine cases of the right posterior sectoral duct opening into the choledochal cyst are reported [1-8]. AHD is not easily detected on cholangiography as it may be displaced by the choledochal cyst or may be overshadowed by the denser image of the choledochal cyst

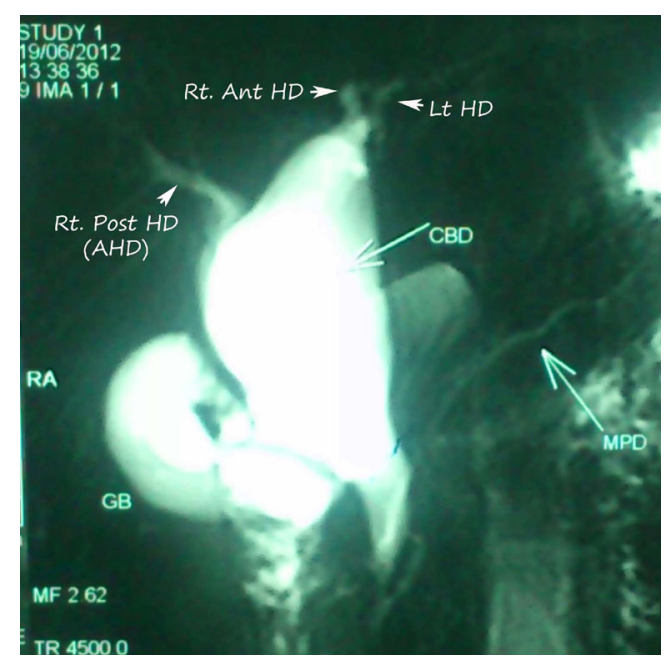

Fig. 1 MRCP showing aberrant right posterior sectoral duct $(A H D)$ opening into the choledochal cyst, and common hepatic duct being formed by right anterior sectoral duct and left hepatic duct 
$[2,6]$. In earlier case reports, AHD was diagnosed during or after cyst excision, on repeated ERCP, intra-operative cholangiography, intra-operative endoscopy or on 3D MRCP [2, 6-8]. Ligation or missed AHD during surgery may lead to complications like cholangitis, liver abscess, liver atrophy, cirrhosis, biliary fistula or biliary peritonitis. AHD can be anastomosed with the Roux-en-Y jejunal loop separately or after merging with the common hepatic duct if both ducts are nearby $[3,4,8]$. We followed up on the patient with liver function test and ultrasound, of which results were within the normal limits. HIDA scan is valuable in assessing the patency of biliary enteric anastomosis, but it was not performed because the patient was reluctant for it.

\section{References}

1. Todani T, Watanabe Y, Toki A, Sato Y, Ogura K, Yamamoto S et al (1997) Ductoplasty for an aberrant hepatic duct in a choledochal cyst. Pediatr Surg Int 12:618-619
2. Takahashi T, Shimotakahara A, Takahashi T, Lee KD, Lane GJ, Okazaki T et al (2008) Choledochal cyst associated with an accessory hepatic duct identified by intra-operative endoscopy: case report and literature review. Pediatr Surg Int 24:1079-1082

3. Todani T, Watanabe Y, Toki A, Ogura K, Wang ZQ (1998) Coexisting biliary anomalies and anatomical variants in choledochal cyst. Br J Surg 85:760-763

4. Sarin YK (2005) Biliary ductal and vascular anomalies associated with choledochal cyst. J Indian Assoc Pediatr Surg 10:86-88

5. Blumgart LH, Hann LE (2012) Surgical and radiologic anatomy of the liver, biliary tract, and pancreas. In: Jarnagin WR, Jacques Belghiti J, Büchler MW et al (eds) Blumgart's surgery of the liver, biliary tract, and pancreas, 5th edn. Elsevier Saunders, Philadelphia, pp 31-57

6. Narasimhan KL, Chowdhary SK, Rao KL (2001) Management of accessory hepatic ducts in choledochal cysts. J Pediatr Surg 36:1092-1093

7. Geraci G, Nigro CL, Sciuto A, Arnone E, Modica G, Sciumè C (2011) Surgical treatment of choledochal cyst associated with an aberrant posterior hepatic duct: report of a case and brief literature review. Case Rep Gastroenterol 5:73-81

8. Saito T, Hishiki T, Terui K, Sato Y, Mitsunaga T, Terui E et al (2011) Use of preoperative, 3-dimensional magnetic resonance cholangiopancreatography in pediatric choledochal cysts. Surgery 149:569-575 